\title{
THE ROLE OF SHOT PEENING IN INCREASING X70 STEEL FATIGUE PROPERTIES
}

The paper presents the authors' results of experimental examination of pipeline steel X70 fatigue properties before and after shot peening application, including relaxation of residual stresses during rotating bendi $n g$ fatigue loading $\left(f=30 \mathrm{~Hz}, \mathrm{~T}=20 \pm 5^{\circ} \mathrm{C}, R=-1\right)$. The obtained results confirmed the positive effect of surface hardening realized by shot peening. The fatigue properties incl. fatigue limit were higher after shot peening and this effect was visibly higher for notched specimens than for smooth specimens. During rotating bending fatigue loading the residual stresses in subsurface layers relaxes which decreases the strengthening effect after a certain number of cycles.

Keywords: X70 steel; shot peening; fatigue properties

\section{Introduction}

The fatigue of structural materials is a phenomenon which has been continuously investigated more than 170 years. The fatigue properties obtained by experimental techniques are very important, especially with regards to safety, reliability of engineering components and constructions, which is closely connected with economy and ecology of production [1-3].

Natural gas is transported through big distances in pipes under high pressure. Due to the friction of the gas with the pipe and turbulences caused by fittings and bent adapters the value of the pressure inside the pipe decreases. To restore the pressure it is necessary to periodically add compressor stations into the pipe system. Vibrations created by compressors and rapid pressure changes in the pipes cause fatigue damage of used material. Several methods of non - destructive testing as a penetration test, magnetic particle test and so on are used to identify propagating fatigue cracks [4]. Damage of a high pressure gas pipe is usually followed by big explosion which causes devastating disaster. These are the reasons why it is necessary to increase fatigue life of X70 steel used for high pressure gas pipes [5].

Deformation strengthening of the surface layer is one of the methods used to increase time necessary for a fatigue crack initiation. Due to a difficult shape of gas pipes not all the methods of surface hardening can be used. One of suitable methods, which is possible to use on gas pipes is shot peening. Shot peening is a cold - working process of surface treatment, where the surface is bombarded with small and hard spherical media called shots. Impact of every shot causes a plastic deformation of the surface and a dimple is created $[6,7]$. Tension deformation necessary for creation of a dimple causes compression residual stress in the subsurface layers of the material. This compression residual stress mainly increases the time necessary for fatigue crack initiation which increases the total fatigue life of a component or a construction.

The measurement of residual stress by X-ray diffraction (XRD) relies on the fundamental interactions between the wave front of the X-ray beam and the crystal lattice. By residual stress measuring using X-ray diffraction (XRD), the strain in the crystal lattice is measured and the associated residual stress is determined from the elastic constants assuming to a linear elastic distortion of the appropriate crystal lattice plane. Since X-rays impinge over an area for about $2 \mathrm{~mm}^{2}$ on the sample, many grains and crystals will contribute to the measurement. The exact number is dependent on the grain size and beam geometry. Although the measurement is considered to be near surface, X-rays do penetrate some distance into the material: the penetration depth depends on the anode, material and angle of incidence. Hence the measured strain is usually over a few microns depth under the surface of the specimen [8].

In this paper the authors publish their own results of experimental examination of pipeline steel X70 fatigue properties before and after shot peening application including relaxation of residual stresses during rotating bending fatigue loading.

\section{Experimental part}

Results of quantitative chemical analysis of X70 steel are listed in Table 1. They show that the steel has a very low carbon content

\footnotetext{
${ }^{*}$ Katarina Mikova ${ }^{1}$, Mario Guagliano ${ }^{2}$, Otakar Bokuvka ${ }^{1}$, Libor Trsko ${ }^{1}$, Frantisek Novy ${ }^{1}$

${ }^{1}$ Department of Materials Engineering, Faculty of Mechanical Engineering, University of Zilina, Slovakia, E-mail: katarina.mikova@fstroj.uniza.sk

${ }^{2}$ Department of Mechanics, Politecnico di Milano, Milano, Italy
} 
(because very good weldability is required) and two microalloying elements $\mathrm{Nb}$ and $\mathrm{V}$ which increase the toughness of material. Microstructure of experimental X70 steel (Fig. 1, Fig. 2) consists of polyedric grains of ferrite and perlite. The microstructure has a very strong deformation texture (ferrite and pearlite grains create rows) which was caused by the rolling of X70 steel during its manufacturing.

Chemical composition of X70 steel (in weight \%)

Tab. 1

\begin{tabular}{|c|c|c|c|c|c|c|c|}
\hline $\mathrm{C}$ & $\mathrm{Si}$ & $\mathrm{Mn}$ & $\mathrm{P}$ & $\mathrm{S}$ & $\mathrm{Nb}$ & $\mathrm{V}$ & $\mathrm{Fe}$ \\
\hline 0.09 & 0.30 & 1.71 & 0.016 & 0.002 & 0.05 & 0.06 & balance \\
\hline
\end{tabular}

Mechanical properties of X70 steel

Tab. 2

\begin{tabular}{|c|c|c|}
\hline$R_{m}(\mathrm{MPa})$ & $R_{e}(\mathrm{MPa})$ & $A(\%)$ \\
\hline 605 & 495 & 21.6 \\
\hline
\end{tabular}

Mechanical properties (Table 2) show medium tensile strength and high elongation which makes a good assumption that shot

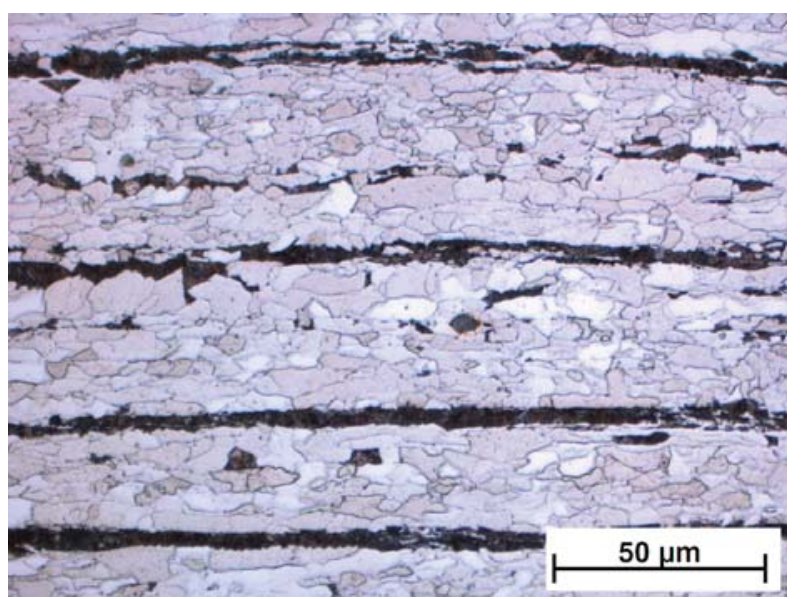

Fig. 1 Microstructure of X70 steel, longitudinal cut, etch. Nital

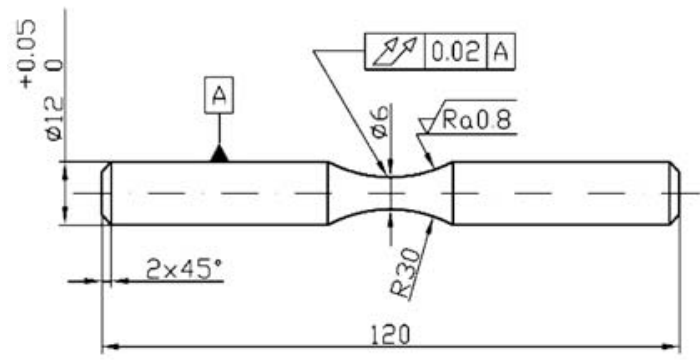

Fig. 3 Shape and dimensions of smooth specimens for fatigue tests peening treatment could create strengthened surface layers which would increase the time necessary for fatigue crack initiation. From X70 steel sheet metal of thickness $14 \mathrm{~mm}$ were cut pieces in longitudinal direction, which were machined to obtain 21 pieces of round specimens and 21 pieces of notched specimens for rotating bending fatigue tests. Rotating bending fatigue tests with parameters: frequency $f=30 \mathrm{~Hz}$, temperature $T=20 \pm 5{ }^{\circ} \mathrm{C}$ and stress ratio $R=-1$, were carried out on the as - machined and shot peened smooth specimens and on as - machined and shot peened notched specimens with geometry according to ISO 1143 [9], Figs. 3 and 4 . The shot peening treatment of specimens [10] was realized with the use of parameters including Almen intensity presented in Table 3.

Parameters of performed shot peening treatment

Tab. 3

\begin{tabular}{|c|c|c|}
\hline Shot type and diameter $(\mu \mathrm{m})$ & Almen Intensity & Coverage $(\%)$ \\
\hline S $170($ steel, $\varnothing=425 \mu \mathrm{m})$ & $8 \mathrm{~A}$ & 100 \\
\hline
\end{tabular}

Microhardness measurement on the cross section of specimens was carried out by Vickers method at a loading weight $200 \mathrm{~g}$ for

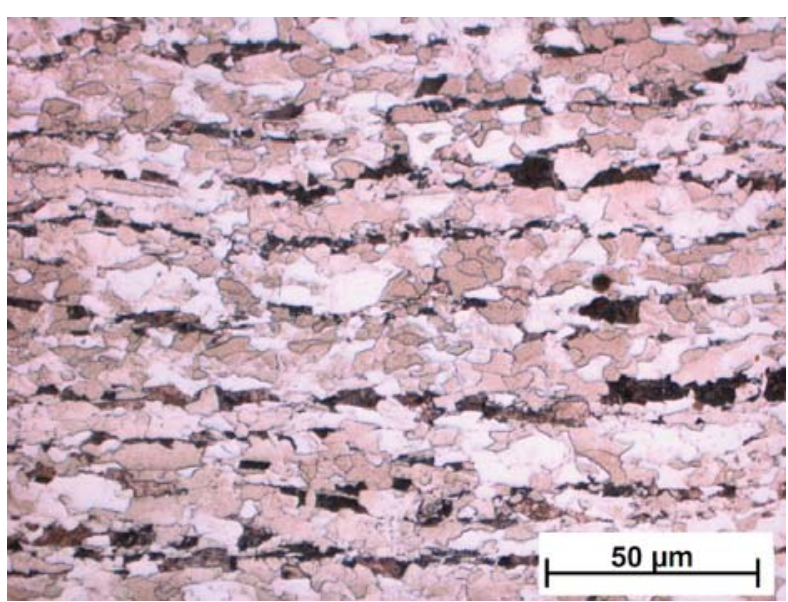

Fig. 2 Microstructure of X70 steel, transversal cut, etch. Nital

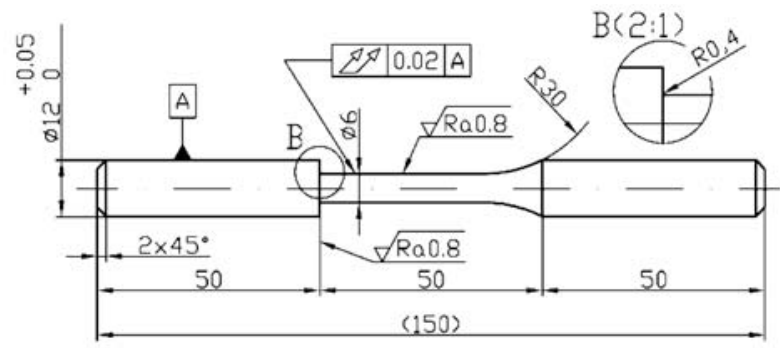

Fig. 4 Shape and dimensions of notched specimens for fatigue tests 


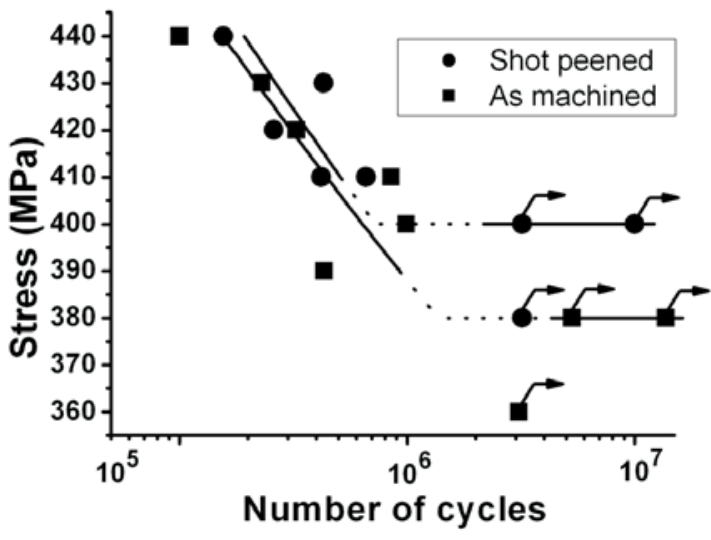

Fig. $5 S-N$ curves of $X 70$ steel before and after shot peening application (smooth specimens)

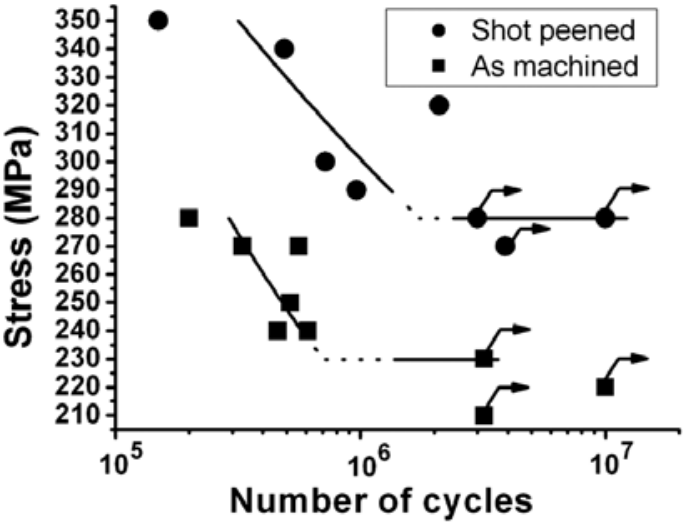

Fig. $6 \mathrm{~S}-\mathrm{N}$ curves of steel X70 before and after shot peening application (notched specimens)
$15 \mathrm{~s}$. To study the state of residual stresses, XRD analysis was performed on all series of specimens using an AST X-Stress $3000 \mathrm{X}$ ray diffractometer (radiation $C_{r} K_{a}$, irradiated area $2 \mathrm{~mm}^{2}, \sin 2 \psi$ method, diffraction angles $(2 \theta)$ scanned between $-45^{\circ}$ and $45^{\circ}$ ). Measurements were carried out in depth step by step removing a very thin layer of material using an electro - polishing device in order to obtain the in - depth trend of residual stresses. A solution of acetic acid (94\%) and perchloric acid (6\%) was used for electro - polishing.

\section{Results and discussion}

Results of fatigue tests, the dependence of rotating bending stress vs. number of cycles to failure (or run out), $S-N$ curves, obtained in the region from $N \approx 10^{5}$ cycles to $N \approx 10^{7}$ cycles for smooth specimens and notched specimens are shown in Figs. 5 and 6. According to these figures it is obvious that the fatigue life-

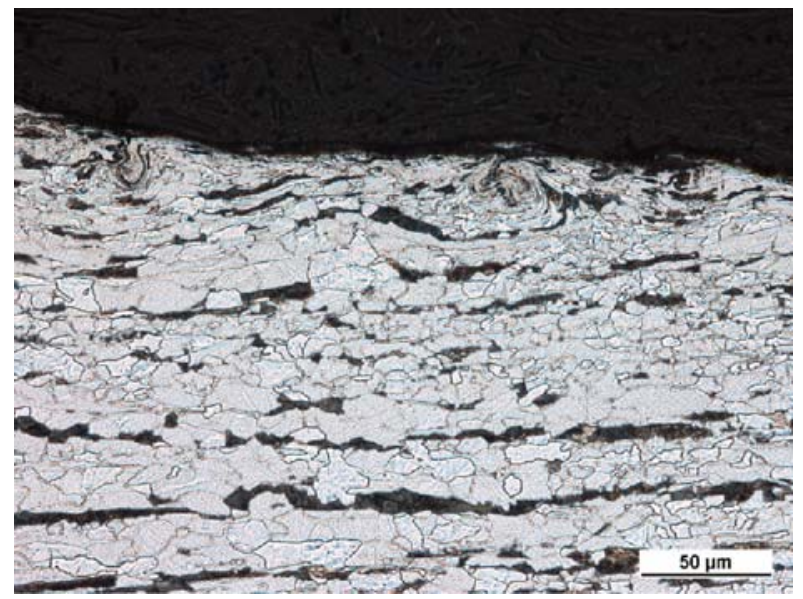

Fig. 7 Surface morphology of X 70 steel after shot peening application, etch. Nital time continuously increases with the decrease of rotating bending loading. The results after shot peening application obtained for the smooth specimens and notched specimens are also shifted to a higher number of cycles, to the right side of the plot, and it entails better fatigue properties. The fatigue limit $\sigma_{o c}$ was determined at the run - out number of $N=3 \times 10^{6}$ cycles with using a staircase procedure. Fatigue limit $\sigma_{o c}$ in the case of smooth as machined specimens was $\sigma_{o c}=380 \mathrm{MPa}$ and for shot peened specimens $\sigma_{o c}=400 \mathrm{MPa}$, the increase is $5.26 \%$, Fig. 5. The fatigue ratio $\sigma_{o c} / R_{m}$ increased from $\sigma_{o c} / R_{m}=0.628$ to $\sigma_{o c} / R_{m}=0.661$. In the case of notched as machined specimens the fatigue limit $\sigma 0 c$ was $\sigma o c=230 \mathrm{MPa}$ and for shot peened specimens $\sigma_{o c}=280 \mathrm{MPa}$, the increase is $24.73 \%$, Fig. 6 . The fatigue ratio $\sigma_{o c} / R_{m}$ increased from $\sigma_{o c} / R_{m}=0.380$ to $\sigma_{o c} / R_{m}=0.462$. The influence of shot peening application on the fatigue properties, resistance against fatigue degradation mechanisms is visibly higher for notched specimens than for smooth specimens. These results are in good agreement with works [11, 12], where an increase of fatigue properties

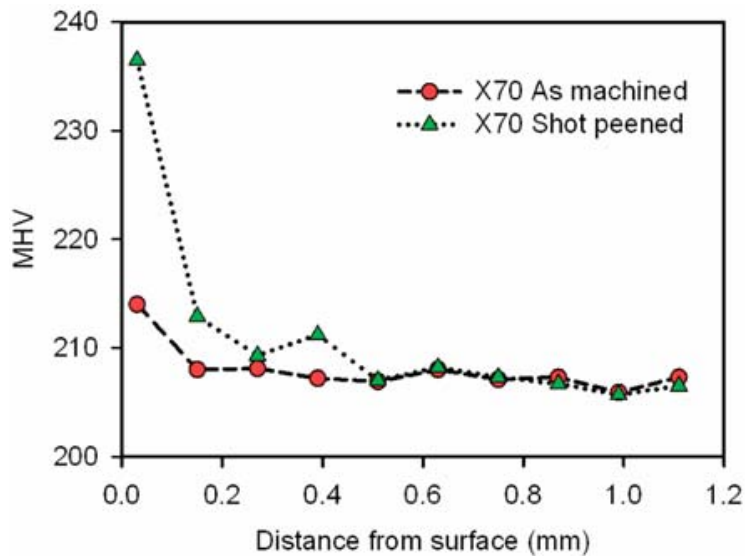

Fig. 8 Surface layers microhardness values, X70 steel, before and after shot peening application

$96 \cdot$ COMMUNICATIONS 4/2012 
after application of shot peening on the surface of the structural materials is presented; the fatigue properties of structural materials can be increased up - to $20 \%$. Better fatigue properties of X70 steel after shot peening are the result of quantitative changes in the surface layers; the characteristic surface morphology is created (Fig. 7), mechanical and technological properties are changed, Figs. 8 and 9. The characteristic surface morphology is the result

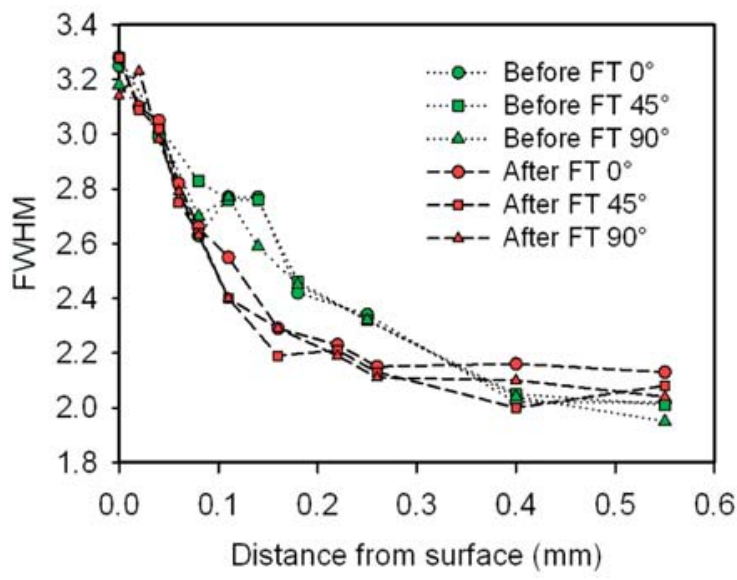

Fig. 9 FWHM profile, X70 steel, before and after fatigue tests

of multiple impacts of the shots on the surface of the specimens, an indentation is created which is surrounded by a plastic region followed by an elastic zone Fig. 7. The surface morphology changes are accompanied usually with increased surface hardness (Fig. 8) and FWHM (Full With at Half Maximum), Fig. 9, due to the cold - working effect of shot peening [13]. Microhardness is higher at the surface (237 MHV) and with gradually increasing depth in a direction to the axis it has a decreasing character (207 MHV for the core of material). The variation of microhardness values is caused by different orientation and deformation of grains. The parameter FWHM shown in Fig. 9, measured by X - ray diffraction (XRD) represents the full width of the diffraction peak at half of the maximum intensity and it is assumed as an index of hardening of the material. As it is observed in Fig. 9 the on - surface amount of FWHM is growing with increasing kinetic energy of the shot peening process. It is to be noted that the thickness of the work - hardened layer can be estimated as the thickness of the layer which shows considerably increased FWHM values in comparison with the core of material. The microhardness is closely related to FWHM and residual stresses which represents resistance of material to local plastic deformation. The decrease of microhardness and FWHM corresponds to the decrease of residual stresses (see Figs. 8, 9 vs. Fig. 10). Relaxation of residual stresses can be observed by comparing the residual stresses of specimens before fatigue test and residual stresses of specimens after fatigue test, Fig. 10.

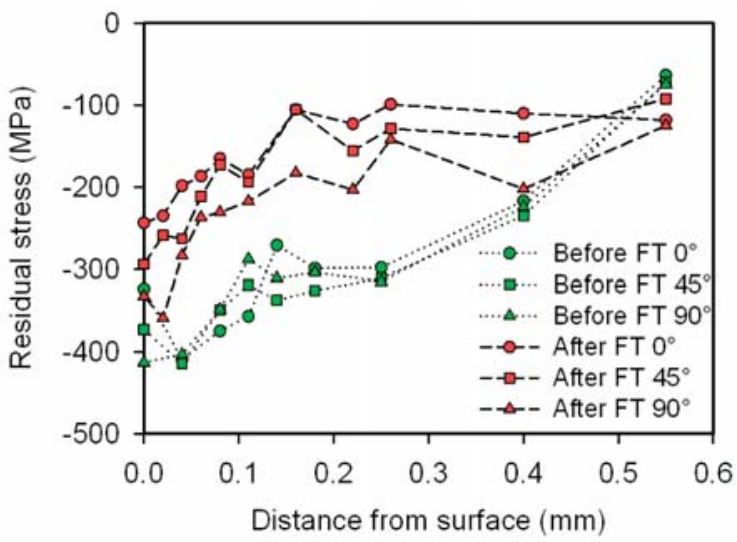

Fig. 10 Distribution of residual stresses, X70 steel, shot peened specimens before and after fatigue tests

Residual stresses of specimens after fatigue tests had comparable values on the surface with the specimens before fatigue tests, but it is obvious that after the fatigue test the values of residual stresses decrease much faster and reach minimum in a smaller depth than specimens before fatigue tests. This means that during cyclic loading the residual stresses in the surface and subsurface layers relax which lowers the strengthening effect and lowers the fatigue lifetime of metallic components [12].

\section{Conclusions}

With regard to the obtained results of X70 pipeline steel at rotating bending fatigue tests $\left(f=30 \mathrm{~Hz}, T=20 \pm 5^{\circ} \mathrm{C}, R=-1\right)$ it can be stated:

- shot peening application causes deformation strengthening of surface layers of tested steel,

- fatigue limit determined for smooth as - machined specimens was $\sigma_{o c}=380 \mathrm{MPa}$ and for smooth shot peened specimens $\sigma_{o c}=400 \mathrm{MPa}$,

- fatigue limit determined for notched as - machined specimens was $\sigma_{o c}=230 \mathrm{MPa}$ and for notched shot peened specimens $\sigma_{o c}=280 \mathrm{MPa}$,

- increase of fatigue limit $\sigma o c$ after shot peening application was visibly higher for notched specimens than for smooth specimens,

- during rotating bending fatigue loading the residual stresses in subsurface layers relax, whhich lowers the strengthening effect after a certain number of cycles,

- the role of shot peening as a cold - working process at increasing of X70 steel fatigue properties is positive.

\section{Acknowledgements}

The research was supported by the Scientific Grant Agency of the Ministry of Education, Science and Sports of the Slovak Republic and Slovak Academy of Sciences, grant No. 1/0743/12. 


\section{COMMNICAIIONS}

\section{References}

[1] BOKUVKA, O. et al.: Low and High Frequency Fatigue Testing, EDIS, ZU Zilina, 2000

[2] KUNZ, L.: Experimentalni stanoveni unavovych charakteristik materialu [Experimental Evaluation of Materials Fatigue Characteristics], EDIS, ZU Zilina, 2003 (in Czech)

[3] BURSAK, M., BOKUVKA, O.: Communications - Scientific Letters of the University of Zilina, 4, 2006

[4] LEITNER, B. et al.: Nedestruktivne skusanie materialov v plynarstve, [Nondestructive Testing of Materials in Gas Industry], EDIS ZU Zilina, 2003

[5] GAJDOS, L. et al.: Structural Integrity of Pressure Pipelines, PRAAM, Prague, 2004

[6] ABADIE, F. et al.: Shot Peening: A Dynamic Application and its Future - 2. edition, Wetzikon, Metal Finishing News, 2009

[7] Metal Improvement Company: Shot Peening Applications. 2010. [online]. [cit. 2012-08-14] Available on the internet: <www.metalimprovement.net.cn/documents/english_lit/MIC_Green_Book_9th_Edition.pdf>

[8] FITZPATRICK, M.E. et al.: Measurement Good Practice Guide No. 52: Determination of Residual Stresses by X-Ray Diffraction - 2. edition, Teddington : NPL, 2005

[9] ISO 1143: 1975. Metals - Rotating Bar Bending Fatigue Testing

[10] PEEN SERVICE - NORBLAST GROUP s. r. 1.: Surface Engineering - Propagation Handbook of Company, 2011

[11] BAGHERIFARD, S., GHELICHI, R.: Experimental and Numerical Analysis of Surface Nanostructured Materials Obtained by High Energy Shot Peening, Convegno Nazionale IGF, 2009

[12] GUAGLIANO, M. et al.: Influence of Surface Hardening on Fatigue Properties of AISI 16Ti Stainless Steel. $29^{\text {th }}$ Intern. Colloquium Advanced Manufacturing and Repair Technologies in Vehicle Industry. EDIS, ZU Zilina, 2012

[13] SHAW, L. L. et al.: A Direct Comparison in the Fatigue Resistance Enhanced by Surface Severe Plastic Deformation and Shot Peening in a C-2000 Superalloy. Materials Science and Engineering, 2010. 